\title{
1 Incidence and circumstances of falls among middle-aged women: a cohort study
}

2 Mengmeng Wang, MMSc, ${ }^{1}$ Feitong Wu, $\mathrm{PhD},{ }^{1}$ Michele L. Callisaya, $\mathrm{PhD},{ }^{1,2}$ Graeme Jones, $3 \mathrm{PhD},{ }^{1}$ and Tania Winzenberg, $\mathrm{PhD}^{1}$

41 Menzies Institute for Medical Research, University of Tasmania, Hobart, Tasmania, Australia

52 Peninsula Clinical School, Central Clinical School, Monash University, Australia

6 Address correspondence to: Feitong $\mathrm{Wu}, \mathrm{PhD}$, Menzies Institute for Medical Research

7 University of Tasmania, 17 Liverpool Street, Hobart, Tasmania 7000.

$8 \quad$ E-mail: Feitong.Wu@utas.edu.au

\section{Acknowledgements}

10 We thank all the volunteers and participants involved in the present study.

11 Funding: This work was supported by the National Health and Medical Research Council and 12 a Menzies Institute for Medical Research NHMRC (the National Health and Medical Research 13 Council) development grant. Feitong $\mathrm{Wu}$ is supported by a National Health and Medical 14 Research Council Early Career Fellowship (APP1158661). Michele Callisaya is supported by 15 a National Health and Medical Research Council Boosting Dementia Leadership Fellowship 16 (APP1135761). 


\section{Mini-Abstract}

2 This was the first study assessing falls prospectively in middle-aged women. The one-year

3 incidence was $42 \%$ for any fall, which suggest falls are a major issue in middle-aged women.

4 Middle-aged women, particularly those sustaining a fall, could be a target group for falls 5 prevention strategies.

6

7

8

9

10

11

12

13

14

15

16

17

18

19

20

21

22

23

24

25

26

27

28

29 


\section{$1 \quad$ Abstract}

2 Purpose: Incidence and circumstances of falls in middle-aged people are poorly understood.

3 This cohort study aimed to elucidate the incidence and circumstances of falls over one year in

4 middle-aged women.

5 Methods: Falls were recorded monthly for one year by questionnaire in 2017-2019 in a

6 population-based sample of women aged 41-62 years. The incidence of falls and injurious falls,

7 and related circumstances were descriptively analysed.

8 Results: Of 273 women, 115 sustained 209 falls. The one-year incidence was $42 \%$ for any fall,

$9 \quad 17 \%$ for multiple (two or more) falls, and $24 \%$ for injurious falls. The incidence was greater in

10 older age groups for any fall $(33 \%, 45 \%$ and $44 \%$ for people aged $<50,50-55$, and $>55$ years,

11 respectively), multiple falls $(7 \%, 14 \%$, and $22 \%)$ and injurious falls $(15 \%, 20 \%$, and $28 \%)$,

12 although only the incidence of multiple falls was significantly increased across the three age 13 groups $(P=0.01)$. Most falls occurred outdoors $(71 \%)$ and were attributed to tripping and 14 slipping (60\%).

15 Conclusions: Falls are a major issue in middle-aged women, a group that has been largely 16 ignored in the prevention of falls. Middle-aged women, in particular those sustaining a fall, 17 could be a target group for falls prevention strategies. Future studies are needed to identify risk 18 factors for falling in this population so as inform the development of strategies for preventing 19 falls in middle-aged women.

20 Keywords: descriptive analysis, injury, location, cause, longitudinal study 


\section{$1 \quad$ Introduction}

2 Falls are a major public health issue among older people, being the second leading cause of 3 unintentional injury-related mortality worldwide [1]. Around thirty to forty percent of 4 community-dwelling persons over the age of 65 fall each year [2,3] and women have a higher 5 risk than men [4]. Retrospective data suggest that falls may occur at a similar rate in middle6 aged and older people [5], but this has not been confirmed with prospective data and the 7 incidence and circumstances of falls in this age group is poorly studied. Nonetheless, the 8 disability-adjusted life years (DALYs) caused by falls in middle-aged adults is estimated to be

910620 thousand worldwide [6]. Because a previous fall is one of the strongest risk factors for 10 future falling [4], preventing falling in middle age may also help to prevent falls in older age.

11 Previous studies of falls in middle-aged adults have only assessed prevalence of falls 12 retrospectively over periods ranging from the previous 3 months to two years, with the 13 prevalence ranging from 12 to $25 \%$ [5,7-9]. However, these retrospective data are subject to 14 recall bias [10], that can lead to substantial underestimation of the rate of falls, by up to $32.8 \%$ 15 [11]. To that end, prospective recording of falls at least once a month over 6 to 12 months is recommended by the Prevention of Falls Network Europe and Outcomes Consensus Group

$17[12,13]$. However, no studies have assessed the incidence and circumstances of falls measured 18 prospectively in middle-aged women. Addressing this evidence gap could help develop tailored 19 prevention strategy for falls in this age group of women. Therefore, the aim of our study was to describe the incidence and circumstances of falls over one year in middle-aged women.

\section{Methods}

\section{Participants}

23 This is a one-year prospective cohort study assessing falls in middle-aged women between 24 2017-2019. Participants were recruited from 470 women who were randomly selected from the 
1 Tasmania electoral roll and participated in a 2-year randomised controlled trial (RCT) of an

2 osteoporosis education intervention in $2000[14,15]$ who were further followed up in 2011-

32012 [16]. We invited all women who participated in the 2011-2012 follow-up (n=347) to

4 participate in the current study. The details of the original RCT and 2011-2012 follow-up study

5 have been described elsewhere [14-16]. The study did not include any education around falls.

6 Briefly, participants were excluded from the original RCT if they had: previous measurement

7 of bone density, thyroid disease, renal failure, malignancy, rheumatoid arthritis, a history of

8 hysterectomy or hormone replacement therapies, pregnancy or planning pregnancy within 2

9 years of study entry, or were lactating. This study was approved by the Tasmania Health and

10 Medical Human Research Ethics Committee (H0016156), and all participants gave written

11 informed consent.

\section{Measurement of falls}

13 A fall was defined as 'an unexpected event in which the participant comes to rest on the ground, 14 floor, or lower level'[13]. Incidence of falls was assessed monthly for 12 months by questionnaire. The questionnaire asked if the participant had any falls in the month, and if yes, the dates, location and any reason of the fall(s), and any injuries from the fall(s). An injurious fall was defined as at least one fall that caused any injuries in the month. They were asked to record any fall for each month. Participants were given three months of questionnaires at a time and returned them via a pre-paid envelope. If questionnaires were not returned within two weeks of the end of each three months, a research assistant phoned participants to confirm if

21 there were any falls.

\section{Anthropometric and other factors}

23 Height was measured to the nearest 0.1 centimetre $(\mathrm{cm})$ by a stadiometer (The Leicester height measure, Invicta Plastics Ltd, Oadby, England), with shoes, socks, and headgear removed. 
1 Weight was measured to the nearest 0.1 kilogram $(\mathrm{kg})$ by a single set of calibrated scales

2 (Heine, Dover NH USA) with shoes and heavy clothing removed. Body mass index (BMI) was

3 calculated as weight $/$ height $^{2}\left(\mathrm{~kg} / \mathrm{m}^{2}\right)$.

4 We used a standardised questionnaire to collect education level (4 point scale: less than grade

510 , up to grade 10, completed grade 12, tertiary), smoking history (current/former/never),

6 marital status (single, married and living together, married but separated, unmarried but living

7 together, divorced), hours of employment (0, less than or equal to 20 or $>20$ hours per week),

8 family history of osteoporosis and fracture/broken bone, history of fractures in the participant,

9 use of oral contraceptive, and menopausal status (post-menopause, pre-menopause, not clear,

10 peri-menopause).

\section{Statistical analyses}

12 The characteristics of participants are presented using mean (standard deviation, SD) for 13 continuous variables, and number (\%) for categorical variables. We compared the 14 characteristics of participants with and without falls by using chi-squared or Fisher's exact test 15 for categorical variables as appropriate, and Student's $t$-test for continuous variables. We were 16 interested in potential differences in falls in those aged $<50$ years, $50-55$ years and older than 1755 years as 1) age 50-55 years is a stage when people begin to pass from middle to old age, 18 especially with menopause in women [17]; 2) balance and muscle strength begin to decline 19 sharply after $45-55$ years $[18,19]$. However, because of the age distribution of participants, we were only able to meaningfully categorise the falls data by three age groups $(<50,50-55,>55$ 21 years). The incidence of any fall, multiple falls and injurious falls and the frequency 22 distributions of location, causes, and season of falls for these three age groups were presented 23 as number (\%). To examine the increasing trend towards the incidence of falls across the three age groups, Wilcoxon Rank Sum test was used. The differences in the three age groups 
1 regarding the circumstances of falls were tested using chi-squared or Fisher's exact test as

2 appropriate. A two-sided $P$ value $<0.05$ was considered statistically significant. All statistical analyses were conducted using Stata version 16.0 (Stata Corp, College Station, TX, USA).

\section{$4 \quad$ Results}

\section{Characteristics of the participants}

6 In recruiting for the original 2-year randomised controlled trial, 470 of 739 eligible women

7 invited agreed to participate (response rate of 64\%, aged 25-44 years) [15]. Three withdrew

8 prior to intervention delivery and were not included in subsequent analyses [15]. Two hundred

9 and seventy-eight were retained in the 2017-2019 follow-up (aged 41-62 years). Five of these

10 recorded no falls data, so, 273 participants were included in the present analysis. Of these, all

11 but two completed one-year recording of falls data - these two participants completed 6-months

12 and10-months, respectively. The differences in baseline characteristics of the participants who

13 were $(n=273)$ and were not $(n=194)$ included in the current study are shown in Supplementary

14 Table 1 (Online Resource). Participants lost to 2017-2019 follow-up were younger, shorter,

15 less educated, more likely to be former/current smokers compared with those who were

16 included in the present study $(P<0.05$ for all). Other characteristics were similar.

17 Table 1 shows study participants' characteristics of the total sample and for fallers and non-

18 fallers. The characteristics of fallers and non-fallers were similar, except that the proportion of

19 non-smokers and of participants who were unemployed was higher in fallers (72 vs 59\%

$20 P=0.007$ and 22 vs $17 \%, P=0.046$, respectively). Fallers were only slightly older than non-

21 fallers and the difference was not statistically significant (Table 1) but multiple fallers (mean

22 age 56.9 (SD 3.9) years) were older than non-multiple fallers (54.8 (SD 5.3) years) $(P=0.009)$. 
1 The incidence of falls and injurious falls by age group is presented in Table 2. There were 209

2 falls. Forty-two percent of participants $(\mathrm{n}=115)$ suffered at least one fall (any fall), 17\%

3 suffered multiple falls, and 24\% suffered injurious falls (Table 2).

4 The incidence of falls, multiple falls and injurious falls was greater in older age groups, though

5 the difference across age groups was only statistically significant for multiple falls $(\mathrm{p}=0.25$,

$6 \quad 0.01$ and 0.05 for any fall, multiple falls and injurious falls respectively). Thirty-three percent

7 of participants aged $<50$ years sustained at least one fall, rising to $45 \%$ in those aged $50-55$

8 years, and $44 \%$ in those aged $>55$ years. The incidence of multiple falls was $7 \%$ in participants

9 aged $<50$ years, $14 \%$ in those aged $50-55$ years, and $22 \%$ in those aged $>55$ years. In addition,

10 the incidence of injurious falls was $15 \%$ in participants aged $<50$ years, $20 \%$ in those aged 50 -

1155 years, and $28 \%$ in those aged $>55$ years.

12 Circumstances of falls by age group

13 Location and causes

14 A summary of the location of falls is presented in Figure 1. Falls were more likely to occur outdoors than indoors ( $71 \%$ and $29 \%$ respectively). The proportion of falls occurring outdoors

16 was similar across the three age groups $(71 \%, 67 \%$, and $72 \%$ in people aged $<50,50-55$, 17 and $>55$ years, respectively) $(P=0.74)$.

18 The causes of falls are presented in Table 3 . There were 230 causes reported for the 209 falls

19 (11 falls had two or more causes). The commonest reported causes were tripping and slipping, 20 accounting for $60 \%$ (35\% and $25 \%$, respectively), followed by environmental hazards (13\%) 21 and loss of balance (11\%). Tripping and slipping were reported more frequently with age rising 22 from $47 \%$ in those aged $<50$ years, to $62 \%$ and $61 \%$ in those aged $50-55$ years and $>55$ years respectively. However, these differences were not statistically significant. 
1 The distribution of falls among the four seasons is shown in Figure 2. Overall, the proportion

2 of falls was slightly higher in summer (29\%, 59 falls) and autumn (27\%, 56 falls), compared

3 to spring $(22 \%, 47$ falls $)$ and winter (22\%, 47 falls). There were statistical differences between

4 the three age groups in the distribution of falls among four seasons; a higher proportion of falls

5 in summer and autumn in those aged 50-55 (39\% and 31\%) and >55 (24\% and 29\%) years

6 compared to that in those aged $<50$ years $(11 \%$ and $11 \%)(P=0.03)$.

\section{Discussion}

8 Our study provides new data about the incidence and the circumstances of falls in middle-aged 9 women. The incidence of any, multiple and injurious falls was high $(42 \%, 17 \%$, and $24 \%$, respectively) and was greater in older age groups, although the increase with age was only statistically significant for those with multiple falls. Most falls occurred outdoors and were mainly caused by tripping and slipping. These findings suggest that falls are a major issue in middle-aged women, a group that has been largely ignored in the prevention of falls. Middleaged women, particularly those sustaining a fall, could be a target group for falls prevention strategies. They also highlight the importance of future studies to identify risk factors for falling so as inform the development of strategies for preventing falls in middle-aged women. Such an approach may also help to prevent falls in old age.

\section{Incidence of falls}

19 The incidence of any fall in the current study was similar to that in prospective studies in older adults $[2,3,20]$ and even higher than in retrospective studies in that population [21-23]. This suggests that falls are a major issue in middle-aged women, and this has not been well recognised in research or clinical practice. The few cross-sectional studies in middle-aged people have reported a wide range of falls rates, ranging from $2.5 \%$ to $31.6 \%$ assessed retrospectively over the past 3 months to 2 years $[24,9,25,26]$. This retrospective assessment 
1 could be the main reason for the lower rates in these studies than ours, as the potential recall

2 bias of the retrospective method could result in underestimation of the rate of falls by up to

$3 \quad 32.8 \%$ compared to prospective methods [11]. Other reasons may also explain the variability

4 in rate of falls between studies. For example, Hong et al. [26] reported a very low rate of falls

5 of $2.5 \%$ during the past 2 years in Koreans aged $45-64$ years (about $50 \%$ females), but of note

6 falling is usually understood by Koreans as the body falling from a higher position to a lower

7 position, without including slipping, sliding down and sitting down because of a missed steps

8 [26]. In addition, about half of the participants in the study by Hong et al. were males [27], who

9 are less likely to fall than females [24].

10 Similarly, the incidences of multiple falls and injurious falls were also higher than in previous 11 cross-sectional studies. These reported the percentage of participants who experienced multiple

12 falls and injurious falls in middle-aged adults during the past 2 years as approximately $7-9 \%$ 13 and 6-15\% respectively [7,9]. Again, the use of retrospective falls assessment in these studies 14 could have led to underestimation, but one study also applied a stricter definition of injurious 15 falls [9]. Older people with multiple falls are more likely to have gait, cognitive, neurological, physiological and muscle-skeletal problems which predispose them to falling, compared to

17 infrequent fallers $[2,20,28]$. However, it is currently unknown if this is the case for those in middle age and further research is needed to understand risk factors for multiple falls in middleaged women. In older adults, multiple fallers considered a high-risk group that should be targeted for prevention of further falls [29]. This may also be the case in middle-aged women but further research is needed to confirm the how best to approach this and the effectiveness of intervening.

\section{Greater incidence of falls with age}


1 The incidence of any, multiple and injurious falls was greater in older age groups. The

2 differences were of sufficient magnitude to be of clinical and public health relevance (around

3 a 50\% higher incidence of any fall after age 50 years, and a tripling and doubling of incidence

4 by age $>55$ years for multiple falls and injurious falls respectively) although only statistically

5 significant in multiple fallers. The small numbers of women in the younger age groups $(n=46$

6 and 65) limited the power of the study to detect age-related differences. Nonetheless, falls

7 incidence was high even in the younger age groups. It might be that better-functioning younger

8 people were also at higher risk of falls due to engagement in greater level of sporting or

9 ambulatory activity, as has been found in prior studies of older people [30]. In contrast to any

10 fall which had a similarly higher incidence in those aged 50-55 and $>55$ years old, the incidence

11 of multiple and injurious falls was higher across all three age groups. Because multiple falls

12 are more likely to be associated with poorer neurological, gait, cognitive, physiological and

13 musculoskeletal function [28,2,20], the increasing incidence of multiple falls with age might

14 suggest a large influence of age-related decline of functional capabilities on the risk of falling.

15 In line with the observation that multiple falls are usually associated with injuries [31], there

16 was a similar age-related pattern of the incident injurious falls. Given the clinical importance

17 of injuries sustained from falls, it is critical to prevent this increasing trend of the incidence of

18 multiple and injurious falls with ageing. A better understanding of the risk factor profiles for

19 different categories for falls in younger women is essential to accomplishing this.

\section{Circumstances of falls}

21 Falls are less likely to occur outdoors with advancing age in older people [32,33]. In contrast, 22 we did not observe an age-related difference in the proportion of falls occurring outdoors. The 23 proportion of $71 \%$ of falls occurring outdoors in the present study is comparable with a 24 previous study of middle-aged adults [7], while somewhat higher than those of studies in older adults (e.g. 50\%) [32]. There is evidence that indoor falls are more likely to be associated with 
1 frailty whilst outdoor falls tend to be partly explained by higher physical activity [34]. This is

2 consistent with our findings that the proportion of falls is slightly higher in Summer and

3 Autumn, when people would undertake more outdoor activities. Thus, the high percentage of

4 outdoor falls in our study might be indicative of a high level of outdoor activity in middle-aged

5 adults and a lesser likelihood of frailty. In addition, we detected sports-related falls and animal-

6 related falls, which might indicate a high level of outdoor activities in our population. With the

7 widespread promotion of an active lifestyle by various health organizations [35-37], ensuring

8 the safety of outdoor activities should be a priority. For example, by properly maintaining

9 sidewalks, curbs, and other outdoor pedestrian spaces, the likelihood of falls can be reduced

10 [34]. Furthermore, pre-sporting assessment of muscle strength and balance appropriate for the

11 sport, as well as good osteoporosis screening and management [29] may assist in reducing

12 injurious falls.

13 Most falls were due to tripping and slipping, particularly in women aged 50 years and over,

14 followed by environmental hazards (for example uneven surfaces or loose gravel) and loss of

15 balance. Although we were not able to identify the causes of tripping and slipping, they seem to be most likely to also be due to environmental factors, such as slopes, obstructed or uneven pathways and ramps [38]. To date, only one community-based cross-sectional study in middleaged women [7], has investigated environmental factors, reporting that uneven surface/steps contributed to the highest percentage of falls. In fact, environmental reasons for falls were cited more frequently in middle-aged adults (30.2\%) compared to older adults (15.8\%) [7]. This further supports the premise that environmental factors may play an important role in the high incidence of falls in middle-aged women. Nonetheless, further research with falls measured prospectively that includes more detailed examination of the circumstances of falls in middleaged women would confirm this and further assist in defining the types of hazards that pose the greatest risk. 


\section{$1 \quad$ Strengths and Limitations}

2 The key strengths of this study are the use of monthly questionnaires to prospectively ascertain

3 the incidence of falls in an under-investigated population - middle-aged women. The study also

4 has several potential limitations. The number of injurious falls might be underestimated

5 because we did not specifically ask whether participants reporting two falls in a month suffered

6 from injuries from one fall or both. However, as this occurred in only four participants this is

7 unlikely to materially affect our results. Detailed information about circumstances were not

8 collected, including specific locations of falls, activities and the purposes of the activities at the

9 time of falling. These details may provide further information about the reasons of fall-related

10 injuries to inform prevention strategies. In addition, the types of fall-related injuries were not

11 asked, and we were not able to evaluate the severity of the consequences of falls, which is

12 important to assess the clinical significance especially for those injuries leading to

13 hospitalisation. Thus, longitudinal studies with more detailed information of falls are required

14 to explore environmental aspects and consequence of falls in middle-aged adults. Selection

15 bias might exist due to the $64 \%$ response rate at recruitment. However, as previously reported,

16 although the proportion of current smokers $(17 \%)$ in the sample was lower than the Tasmanian

17 prevalence of daily smoking (29\%) in women aged 25-44 years in 1998, socioeconomic factors

18 like educational level and unemployment rate approximate the overall population figures [15].

19 Therefore, the original sample is likely to be representative of the general population of that

20 age range in South Tasmania. Another potential limitation is missing data due to drop-out. The

21 women who were lost to follow-up were younger, shorter, less educated and more likely to be

22 former/current smokers compared to those who completed the study and so perhaps more likely

23 to be less healthy than those who participated in this study. This suggests that if anything loss

24 to follow-up might lead to an underestimation rather than overestimation of falls incidence in

25 middle-aged women. 


\section{Conclusions}

2 Falls are a major issue in middle-aged women, a group that has been largely ignored in the

3 prevention of falls. Middle-aged women, especially those sustaining a fall, could be a target

4 group for falls prevention strategies. The results also highlight the importance of future studies

5 to identify risk factors for falling in this population so as inform the development of strategies

6 for preventing falls in middle-aged women. Such early intervention may also be beneficial for

7 preventing falls in later life.

\section{$8 \quad$ Funding}

9 This work was supported by the National Health and Medical Research Council and a Menzies

10 Institute for Medical Research NHMRC (the National Health and Medical Research Council)

11 development grant. Feitong $\mathrm{Wu}$ is supported by a National Health and Medical Research

12 Council Early Career Fellowship (APP1158661). Michele Callisaya is supported by a National

13 Health and Medical Research Council Boosting Dementia Leadership Fellowship

14 (APP1135761).

\section{Ethical approval}

16 All procedures performed in studies involving human participants were in accordance with the

17 ethical standards of the institutional and/or national research committee and with the 1964

18 Helsinki declaration and its later amendments or comparable ethical Standards.

19 Informed consent

20 Informed consent was obtained from all individual participants included in the study.

\section{Conflict of interest}

22 Mengmeng Wang, Feitong Wu, Michele L. Callisaya, Graeme Jones, and Tania Winzenberg declare that they have no conflict of interest. 


\section{$1 \quad$ References}

2 1. WHO (2018) Falls. https://www.who.int/en/news-room/fact-sheets/detail/falls. Accessed

317 November 2019

4 2. Callisaya ML, Blizzard L, Schmidt MD, Martin KL, McGinley JL, Sanders LM, Srikanth

5 VK (2011) Gait, gait variability and the risk of multiple incident falls in older people: a

6 population-based study. Age Ageing 40:481-487

7 3. Delbaere K, Close JC, Brodaty H, Sachdev P, Lord SR (2010) Determinants of disparities

8 between perceived and physiological risk of falling among elderly people: cohort study. BMJ

$9 \quad 341: c 4165$

10 4. Deandrea S, Lucenteforte E, Bravi F, Foschi R, La Vecchia C, Negri E (2010) Risk factors

11 for falls in community-dwelling older people: a systematic review and meta-analysis.

12 Epidemiology 21:658-668

13 5. Verma SK, Willetts JL, Corns HL, Marucci-Wellman HR, Lombardi DA, Courtney TK

14 (2016) Falls and Fall-Related Injuries among Community-Dwelling Adults in the United

15 States. PLoS One 11:e0150939

16 6. Global Burden of Disease Collaborative Network (2018) Global Burden of Disease Study

172017 (GBD 2017) Results. Seattle, United States: Institute for Health Metrics and Evaluation

18 (IHME). http://ghdx.healthdata.org/gbd-results-tool. Accessed 20 November 2019

19 7. Talbot LA, Musiol RJ, Witham EK, Metter EJ (2005) Falls in young, middle-aged and

20 older community dwelling adults: perceived cause, environmental factors and injury. BMC

21 Public Health 5:86

8. Ablett AD, Wood AD, Barr R, Guillot J, Black AJ, Macdonald HM, Reid DM, Myint PK

23 (2018) A high anticholinergic burden is associated with a history of falls in the previous year

24 in middle-aged women: findings from the Aberdeen Prospective Osteoporosis Screening

25 Study. Ann Epidemiol 28:557-562 
1 9. Caban-Martinez AJ, Courtney TK, Chang WR, Lombardi DA, Huang YH, Brennan MJ,

2 Perry MJ, Katz JN, Christiani DC, Verma SK (2015) Leisure-Time Physical Activity, Falls,

3 and Fall Injuries in Middle-Aged Adults. Am J Prev Med 49:888-901

4 10. Mackenzie L, Byles J, D'Este C (2006) Validation of self-reported fall events in

5 intervention studies. Clin Rehabil 20:331-339

6 11. Garcia PA, Dias JM, Silva SL, Dias RC (2015) Prospective monitoring and self-report of

7 previous falls among older women at high risk of falls and fractures: a study of comparison

8 and agreement. Braz J Phys Ther 19:218-226

9 12. Hauer K, Lamb SE, Jorstad EC, Todd C, Becker C, Group P (2006) Systematic review of 10 definitions and methods of measuring falls in randomised controlled fall prevention trials.

11 Age Ageing 35:5-10

12 13. Lamb SE, Jorstad-Stein EC, Hauer K, Becker C (2005) Development of a common

13 outcome data set for fall injury prevention trials: the Prevention of Falls Network Europe

14 consensus. J Am Geriatr Soc 53:1618-1622

15 14. Winzenberg T, Oldenburg B, Frendin S, De Wit L, Jones G (2005) Effects of bone

16 density feedback and group education on osteoporosis knowledge and osteoporosis self-

17 efficacy in premenopausal women: a randomized controlled trial. J Clin Densitom 8:95-103

18 15. Winzenberg T, Oldenburg B, Frendin S, De Wit L, Riley M, Jones G (2006) The effect

19 on behavior and bone mineral density of individualized bone mineral density feedback and

20 educational interventions in premenopausal women: a randomized controlled trial

21 [NCT00273260]. BMC Public Health 6:12

22 16. Wu F, Wills K, Laslett LL, Riley MD, Oldenburg B, Jones G, Winzenberg T (2018)

23 Individualized Fracture Risk Feedback and Long-term Benefits After 10 Years. Am J Prev

24 Med 54:266-274 
1 17. Women's Health Concern (2017) The menopause. https://www.womens-health-

2 concern.org/help-and-advice/factsheets/menopause/. Accessed 8 June 2020

3 18. El Haber N, Erbas B, Hill KD, Wark JD (2008) Relationship between age and measures

4 of balance, strength and gait: linear and non-linear analyses. Clin Sci (Lond) 114:719-727

5 19. Choy NL, Brauer S, Nitz J (2003) Changes in postural stability in women aged 20 to 80

6 years. J Gerontol A Biol Sci Med Sci 58:525-530

7 20. Martin KL, Blizzard L, Srikanth VK, Wood A, Thomson R, Sanders LM, Callisaya ML

8 (2013) Cognitive function modifies the effect of physiological function on the risk of

9 multiple falls--a population-based study. J Gerontol A Biol Sci Med Sci 68:1091-1097

10 21. Greene BR, Doheny EP, Walsh C, Cunningham C, Crosby L, Kenny RA (2012)

11 Evaluation of falls risk in community-dwelling older adults using body-worn sensors.

12 Gerontology 58:472-480

13 22. Lavedan A, Viladrosa M, Jurschik P, Botigue T, Nuin C, Masot O, Lavedan R (2018)

14 Fear of falling in community-dwelling older adults: A cause of falls, a consequence, or both?

$15 \quad$ PLoS One 13:e0194967

16 23. Tromp AM, Pluijm SM, Smit JH, Deeg DJ, Bouter LM, Lips P (2001) Fall-risk screening

17 test: a prospective study on predictors for falls in community-dwelling elderly. J Clin

18 Epidemiol 54:837-844

19 24. Peeters G, Cooper R, Tooth L, van Schoor NM, Kenny RA (2019) A comprehensive

20 assessment of risk factors for falls in middle-aged adults: co-ordinated analyses of cohort

21 studies in four countries. Osteoporos Int 30:2099-2117

22 25. White AM, Tooth LR, Peeters G (2018) Fall Risk Factors in Mid-Age Women: The

23 Australian Longitudinal Study on Women's Health. Am J Prev Med 54:51-63

24 26. Hong GR, Cho SH, Tak Y (2010) Falls among Koreans 45 years of age and older:

25 incidence and risk factors. J Adv Nurs 66:2014-2024 
1 27. Jang SN, Kawachi I, Chang J, Boo K, Shin HG, Lee H, Cho SI (2009) Marital status,

2 gender, and depression: analysis of the baseline survey of the Korean Longitudinal Study of

3 Ageing (KLoSA). Soc Sci Med 69:1608-1615

4 28. Nevitt MC, Cummings SR, Kidd S, Black D (1989) Risk factors for recurrent

5 nonsyncopal falls. A prospective study. JAMA 261:2663-2668

6 29. Waldron N, Hill A, Barker A (2012) Falls prevention in older adults: Assessment and

7 management. Aust Fam Physician 41:930-935

8 30. Callisaya ML, Blizzard L, McGinley JL, Srikanth VK (2012) Risk of falls in older people

9 during fast-walking--the TASCOG study. Gait Posture 36:510-515

10 31. Poss JW, Hirdes JP (2016) Very Frequent Fallers and Future Fall Injury: Continuous Risk

11 Among Community-Dwelling Home Care Recipients. J Aging Health 28:587-599

12 32. Lord SR, Ward JA, Williams P, Anstey KJ (1993) An epidemiological study of falls in

13 older community-dwelling women: the Randwick falls and fractures study. Aust J Public

14 Health 17:240-245

15 33. Bath PA, Morgan K (1999) Differential risk factor profiles for indoor and outdoor falls in 16 older people living at home in Nottingham, UK. Eur J Epidemiol 15:65-73

17 34. Li W, Keegan THM, Sternfeld B, Sidney S, Quesenberry CP, Kelsey JL (2006) Outdoor

18 Falls Among Middle-Aged and Older Adults: A Neglected Public Health Problem. Am J

19 Public Health 96:1192-1200

20 35. Chan KM, Anderson M, Lau EMC (2003) Exercise interventions: defusing the world's 21 osteoporosis time bomb. Bull World Health Organ 81:827-830

22 36. Haskell WL, Lee IM, Pate RR, Powell KE, Blair SN, Franklin BA, Macera CA, Heath

23 GW, Thompson PD, Bauman A (2007) Physical activity and public health: updated

24 recommendation for adults from the American College of Sports Medicine and the American

25 Heart Association. Med Sci Sports Exerc 39:1423-1434 
1 37. Physical Activity Guidelines Advisory Committee (2009) Physical Activity Guidelines

2 Advisory Committee report, 2008. Nutr Rev 67:114-120

3 38. Lord SR, Sherrington C, Menz HB, Close JCT (2007) Falls in Older People: Risk Factors

4 and Strategies for Prevention. 2nd edn. Cambridge University Press, New York

5

6

7 
Table 1 Characteristics of the participants

\begin{tabular}{|c|c|c|c|c|}
\hline & \multirow{2}{*}{ Total $(n=273)$} & \multicolumn{2}{|c|}{ Subgroups by Falling } & \multirow{2}{*}{$P$ value ${ }^{\mathrm{c}}$} \\
\hline & & Faller $(n=115)$ & Non-Faller $(\mathrm{n}=158)$ & \\
\hline Age(years) & $55.2(5.1)$ & $55.4(4.9)$ & $54.9(5.3)$ & 0.44 \\
\hline Height $(\mathrm{cm})$ & $164.0(6.4)$ & $164.3(6.4)$ & $163.8(6.4)$ & 0.55 \\
\hline Weight $(\mathrm{kg})$ & $74.8(16.1)$ & $74.8(15.8)$ & $74.8(16.3)$ & 0.98 \\
\hline Body mass index $\left(\mathrm{kg} / \mathrm{m}^{2}\right)$ & $27.8(5.9)$ & $27.8(5.8)$ & $27.9(6.0)$ & 0.87 \\
\hline Education, $\mathrm{n}(\%)^{\mathrm{a}}$ & & & & 0.07 \\
\hline Primary/High school & $76(28)$ & $24(21)$ & $52(33)$ & \\
\hline High school/college & $59(22)$ & $25(22)$ & $34(22)$ & \\
\hline $\begin{array}{l}\text { University, CAE, or other tertiary } \\
\text { institution }\end{array}$ & $138(50)$ & $66(57)$ & $72(45)$ & \\
\hline Smoking, $\mathrm{n}(\%)^{\mathrm{b}}$ & & & & $0.007 *$ \\
\hline Never & $176(65)$ & $83(72)$ & $93(59)$ & \\
\hline Current smoker & $19(7)$ & $2(2)$ & $17(11)$ & \\
\hline Ex-smoker & $77(28)$ & $30(26)$ & $47(30)$ & \\
\hline Married/defacto, n (\%) & $215(79)$ & $97(84)$ & $118(75)$ & 0.07 \\
\hline Employed, $\mathrm{n}(\%)^{\mathrm{b}}$ & & & & $0.046^{*}$ \\
\hline No & $51(19)$ & $25(22)$ & $26(17)$ & \\
\hline$<20$ hours per week & $46(17)$ & $12(11)$ & $34(22)$ & \\
\hline$>20$ hours per week & $172(64)$ & $76(67)$ & $96(61)$ & \\
\hline Family history of osteoporosis, $\mathrm{n}(\%)$ & $112(41)$ & $51(45)$ & $61(39)$ & 0.30 \\
\hline Family fracture/broken bone, n (\%) & $184(68)$ & $84(74)$ & $100(64)$ & 0.08 \\
\hline History of fracture, $\mathrm{n}(\%)$ & $36(13)$ & $15(13)$ & $21(13)$ & 0.94 \\
\hline Ever use of oral contraceptive, $\mathrm{n}(\%)$ & $261(96)$ & $109(95)$ & $152(97)$ & 0.54 \\
\hline Menopause, $\mathrm{n}(\%)^{\mathrm{b}}$ & & & & 0.20 \\
\hline Postmenopause & $148(54)$ & $70(61)$ & $78(50)$ & \\
\hline Premenopause & $51(19)$ & $20(17)$ & $31(20)$ & \\
\hline Not clear & $18(7)$ & $8(7)$ & $10(6)$ & \\
\hline Perimenopause & $55(20)$ & $17(15)$ & $38(24)$ & \\
\hline
\end{tabular}




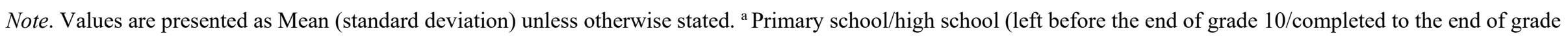
10); high school/college (completed to the end of grade 12); university, College of Advanced Education (CAE), or other tertiary institution. ${ }^{b}$ Numbers in the "Total" column do not always equal to 273 due to a small number of missing values. ${ }^{c} P$ values are for difference in fall status by $c h i$-squared or Fisher's exact tests for categorical variables, and Student's $t$-tests for continuous variables. *denotes statistically significant $(P<0.05)$. 
Table 2 Number (percentage) of people reporting falls by age group during one-year follow-up ( $\mathrm{n}=273$ )

\begin{tabular}{|c|c|c|c|c|c|c|c|c|}
\hline & \multirow{2}{*}{\multicolumn{2}{|c|}{ Total population }} & \multicolumn{6}{|c|}{ Subgroups by age } \\
\hline & & & \multicolumn{2}{|c|}{$<50$ years $(n=46)$} & \multicolumn{2}{|c|}{$50-55$ years $(n=65)$} & \multicolumn{2}{|c|}{$>55$ years $(n=162)$} \\
\hline & Frequency & Percentage & Frequency & Percentage & Frequency & Percentage & Frequency & Percentage \\
\hline \multicolumn{9}{|c|}{ Number of falls } \\
\hline 0 & 158 & 58 & 31 & 67 & 36 & 55 & 91 & 56 \\
\hline 1 & 68 & 25 & 12 & 26 & 20 & 31 & 36 & 22 \\
\hline 2 & 31 & 11 & 3 & 7 & 6 & 9 & 22 & 14 \\
\hline 3 & 3 & 1 & 0 & 0 & 0 & 0 & 3 & 2 \\
\hline 4 & 7 & 3 & 0 & 0 & 1 & 2 & 6 & 4 \\
\hline$\geq 5$ & 6 & 2 & 0 & 0 & 2 & 3 & 4 & 2 \\
\hline \multicolumn{9}{|c|}{ Number of injurious falls } \\
\hline 0 & 208 & 76 & 39 & 85 & 52 & 80 & 117 & 72 \\
\hline 1 & 55 & 20 & 7 & 15 & 11 & 17 & 37 & 23 \\
\hline$\geq 2$ & 10 & 4 & 0 & 0 & 2 & 3 & 8 & 5 \\
\hline Total & 273 & 100 & 46 & 100 & 65 & 100 & 162 & 100 \\
\hline
\end{tabular}


Table 3 Causes of falling among fallers by age group

\begin{tabular}{|c|c|c|c|c|c|c|c|c|}
\hline \multirow[t]{3}{*}{ Causes } & \multirow{2}{*}{\multicolumn{2}{|c|}{ Total population }} & \multicolumn{6}{|c|}{ Subgroups by age } \\
\hline & & & \multicolumn{2}{|c|}{$<50$ years $(\mathrm{n}=46)$} & \multicolumn{2}{|c|}{$50-55$ years $(n=65)$} & \multicolumn{2}{|c|}{$>55$ years $(n=162)$} \\
\hline & Number & Percentage & Number & Percentage & Number & Percentage & Number & Percentage \\
\hline Tripped & 80 & 35 & 4 & 21 & 17 & 33 & 59 & 37 \\
\hline Slipped & 58 & 25 & 5 & 26 & 15 & 29 & 38 & 24 \\
\hline Lost balance & 25 & 11 & 2 & 11 & 1 & 2 & 22 & 13 \\
\hline Legs gave away & 3 & 1 & 0 & 0 & 0 & 0 & 3 & 2 \\
\hline Feel faint & 3 & 1 & 1 & 5 & 1 & 2 & 1 & 1 \\
\hline Feel giddy/dizzy & 0 & 0 & 0 & 0 & 0 & 0 & 0 & 0 \\
\hline \multicolumn{9}{|l|}{ Others } \\
\hline Animal-related & 5 & 2 & 0 & 0 & 3 & 6 & 2 & 1 \\
\hline Sports/activities & 16 & 7 & 1 & 5 & 5 & 10 & 10 & 6 \\
\hline Medical condition & 5 & 2 & 1 & 5 & 3 & 6 & 1 & 1 \\
\hline $\begin{array}{l}\text { Environmental } \\
\text { hazards }\end{array}$ & 28 & 13 & 4 & 22 & 4 & 8 & 20 & 12 \\
\hline $\begin{array}{l}\text { Being knocked } \\
\text { over }\end{array}$ & 4 & 2 & 0 & 0 & 1 & 2 & 3 & 2 \\
\hline $\begin{array}{l}\quad \text { Rolled ankle/give } \\
\text { away knee (no detailed } \\
\text { reason given) }\end{array}$ & 3 & 1 & 1 & 5 & 1 & 2 & 1 & 1 \\
\hline Total & 230 & 100 & 19 & 100 & 51 & 100 & 160 & 100 \\
\hline
\end{tabular}

Note. 230 causes for 209 falls. The number of causes is larger than the number of falls as some participants gave more than one reason for each fall. The category of causes for falling includes five options (tripped, slipped, lost balance, legs gave away, feel faint, feel giddy/dizzy) and one open answer (others). When participants thought the five options did not fit the reason of their falling, they wrote the specific reason on the item of "others" (Of "others", environmental hazards refer to falls that were caused by unsafe surrounding such as uneven surface or loose gravel; animal-related refers to walking the dog or being pushed over by a dog or other animals).

There was no statistical difference in the three age groups by chi-squared test for causes of falling $\left(\chi^{2}=2.63\right.$, P=0.62) (Lost balance, legs gave away, feel faint, feel giddy/dizzy, and others are combined as one category due to the small sample size of these causes when conducting chi-squared test). 
Figure captions

Fig. 1 The location of falls by age group

Fig. 2 The proportion of falls in each season by age group

The study was carried out in the southern hemisphere, so spring is from September to November, summer is from December to February, autumn is from March to May and winter is from June to August. 